\title{
¿Qué educación virtual en qué sociedad (alternativa) del conocimiento para el futuro cercano? Un aporte propositivo
}

\section{What virtual education, in what (alternative) knowledge society for the near future? A propositive contribution}

\section{¿Qué educação virtual em que sociedade (alternativa) do conhecimento para o futuro próximo? Um aporte propositivo}

DOI: http://dx.doi.org/10.25087/resur4a1

Beatriz Fainholc ${ }^{1}$

Recibido, 7 de agosto de 2017 Aprobado, 16 de octubre de 2017

\section{Resumen}

Intentar aproximarse a conceptualizar una educación virtual en qué sociedad alternativa de conocimiento para un futuro cercano, representa un gran desafío social, cultural y moral en la cultura digital, de la sociedad de la Big data, de la Humanidades digitales, de la Analítica cultural, de las Learning Machine, y otros. Se trata de esfuerzos de búsqueda de respuestas a las incógnitas que se nos presentan en la enseñanza superior, la investigación y las prácticas educativas. Parecen carecer de la brújula para rescatar la noción de educación en sí misma, o tal vez, pensar que los equipos y software, posean motivos invisibles que impidan su cabal comprensión, aún. En este marco, se instala la pregunta acerca de qué es una sociedad alternativa de conocimiento, y en este contexto, que es educación virtual, como también de la educación convencional, ya que ambas se hallan atravesada por tecnologías.

Se presenta un aporte principista y propositivo de una síntesis creativa, con un desglose de componentes.

Palabras claves: Sociedad alternativa del conocimiento. Educación Virtual. Socioepistemología. Síntesis creativa.

\footnotetext{
${ }^{1}$ Post-Doctora en Educación. Universidad de Illinois. Doctora en Educación. Profesora Titular de la Universidad de La Plata, Buenos Aires, Argentina - Directora del CEDIPROE. Miembro del Claustro de IUSUR - bfainhol@gmail.com

Rev. educ. super. sur glob-RESUR $N^{\circ} 4$ jul. -dic. 2017 e009 ISSN 2393-6789
} 


\begin{abstract}
To intent to conceptualize a virtual education in an alternative knowledge society for a next future, represents a huge social, cultural and moral challenge in the digital culture, Big data society, Digital Humanities, Cultural Analytic, Machine learning, etc. They are efforts to search answers to the many incognita basically to the higher education, research and educational practices. It seems that still don't exists any compass to rescue the notion of education itself, or maybe, to think that electronic equipment and software have their invisible motives. One of the question in this context, is what is an alternative society of knowledge, and then, the virtual education -including the conventional one,crossed by digital technologies-, both of them inscribed in a creative synthesis socio-epistemological proposal.
\end{abstract}

This article presents a proposal for that with some components to apply them.

Keywords: Alternative knowledge society. Virtual education. Socio-epistemology, Creative synthesis

\title{
Resumo
}

Tentar se aproximar a uma conceptualização da educação virtual para uma sociedade alternativa do conhecimento e para um futuro próximo, representa umenorme desafio social, cultural e moral na cultura digital, na sociedade da Big data, Humanidades digitais, da Analíticacultural, das Learning Machine, etc. São conceitos e metodologias que procuram achar respostas as incógnitas que se apresentamno ensino superior, a pesquisa e a as práticas educativas. Mais elas parecem não ter uma bússola para resgatar a noção de educação em si, ou talvez, pensar quais equipamentos e softwares, têm motivos invisíveis que impedem sua compreensão integral. Neste contexto a pergunta é sobre o que é uma sociedade alternativa do conhecimento, e que é, assim, educação virtual, que inclui a educação convencional, pois ambas estão atravessadas por tecnologias, visando a proposta de uma síntese criativa.

Esta contribuição apresenta um aporte baseado em princípios e propositivo nosseus componentes aplicativos.

Palavras-chave: Sociedade do conhecimento alternativa. Educação Virtual Socioepistemologia. Síntese criativa. 


\section{Introducción}

El objeto de este estudio representa un gran desafío social, cultural y moral para la educación en la cultura digital y en la sociedad de la Big data, las Humanidades digitales $^{2}$,(Hayles, 2012), la Analítica cultural ${ }^{3}$ (Manovich, 2007), las Learning Machine ${ }^{4}$ y lo que vendrá.

Muchas incógnitas y sin una brújula aun, para rescatar la noción de educación en sí misma, atravesada por los nuevos medios (Manovich, 2001) en nuestra contemporaneidad. Allí se encuentra la pregunta de qué es y cómo se constituye una sociedad de conocimiento y la inscripción de una educación virtual.

Las respuestas efectivas deben ser de síntesis creativas, que vigoricen la interacción humana hibrida, -física y artificial-, con todas las dimensiones que aparecen y las que no se sabe cuáles aparecerán. Estas incógnitas necesitan de los procesos educativos.

\section{¿Qué significa una educación que produzca conocimiento en una síntesis creativa?}

Pensar que el modelo de inconmensurabilidad, ${ }^{5}$ para la búsqueda de explicaciones del tránsito a nuevos paradigmas, es teóricamente débil y contraproducente desde el punto de vista práctico. Habrá que reconocer que las dimensiones de análisis no son ni estables ni universales ni uniformes sino singulares. En compleja interdisciplina, interdependencia y

\footnotetext{
${ }^{2}$ Humanidades digitales: término que engloba un nuevo campo interdisciplinario que busca entender el impacto y la relación de las TIC en el quehacer de los investigadores en las ciencias sociales, educación y otros.Objetivos: capturar, estructurar, documentar, almacenar crear y distribuir, aplicar y evaluar datos a ser convertidos en conocimiento, y apropiar metodologías digitales tales como las de visualización, modelación y minería de datos, entre otros,

${ }^{3}$ Analítica cultural: análisis de grandes cantidades de información culturalmente significativa. El investigador analizaría las prácticas tecno culturales de los usuarios de medios

sociales sin renunciar a la escala de las prácticas. Desarrolla métodos de investigación basados en el procesamiento de grandes cantidades de información, más visual, aplicándola a la producción de imágenes en un campo y período dado. Se buscan recurrencias y repeticiones de elementos, llamados patrones, que delineen una tendencia interpretable. Propuesta que ya se está aplicando en el campo educativo con la "Analítica del aprendizaje".

${ }^{4}$ Learning machine : son algoritmos, inteligencias autónomas que toman decisiones de modo flexible, y que en interacción con los humanos trabajan con ellos, enuna sociedad a redefinirse de manera drástica.
}

${ }^{5}$ Se refiere a dos magnitudes que no se pueden comparar entre sí. Concepto que proviene de las matemáticas, que define la falta de una unidad común de medida directa y exacta entre dos variables/modelos.

Rev. educ. super. sur glob-RESUR No 4 jul. - dic. 2017 e009 ISSN 2393-6789 
articulación de categorías, conceptos y metodologías que recurren a revisiones epistemológicas y sociológicas serias, entre otros. Se trataría, así, de:

-Hacer referencia al hibridismode la realidad sociocultural, y por ende a los programas educativos electrónicos, que apunta a reconocer coyunturas de la cultura digital, -sobre todo la cultura del software, (Manovich, 2013) que despiertan nuevas inquietudes, a partir desus posibilidades positivas y negativas. Su presencia ineludible es como una bisagra comunicativa, que marca/impone rutas en un marco cultural más amplio, para corresponderse en comportamientos humanos.

-Visualizar la diversidad no suprime, sino que subraya la necesidad de integrar, a través de la capitalización de fortalezas, diversas propuestas enriquecidas a partir de la formulación de valores y criterios, que a su vez deberían servir de marco a las mediaciones tecnológico educativas para la interacción y la navegación electrónica reflexiva, y la consideración respetuosa de las "diferencias sociales y culturales".

- Trabajar en la apropiación de las TIC y formatos asociados útil y productiva para potenciar la toma de conciencia y la expresión democrática personal y grupal, e inscribir los esfuerzos protagónicos en la esfera sociopolítica y discursiva por una (prudente y no consumística) articulación y aplicación de tecnologías en el aprendizaje a lo largo de toda la vida, entendido éste como un concepto sinérgico, abierto y utópico.

Es decir, antes se necesita discutir acerca del cambio en el porqué y el para qué se aprende, en el qué se enseña y en el cómo se lo enseña, que redefiniría la misión dela educación digital/virtual,y, por ende, replantearía su sentido en el marco de progresivas "síntesis creativas".

Por añadidura, se reformula todo, entre ellos, los roles de las instituciones y organizaciones educativas, de los profesores, alumnos, los medios y contenidos: Einstein -ejemplo de mal estudiante- decía que lo importante es hacerse preguntas, a lo que se agrega: en el intercambio con otros (o trabajo colaborativo y en comunidades virtuales de aprendizaje), donde las posibilidades sinérgicas de aprender más y solucionar los problemas se aumentan. 
Parecería que la fertilidad pragmática en estos análisis, -referidos en nuestro caso a una prospectiva sociológica y educativa, ontológica y epistemológica sería una base viable para pensar síntesis creativas.

\section{2. ¿Qué educación para un futuro de qué sociedad del conocimiento?}

Buenas noticias electrónicas y también aspectos contradictorios y problemáticos encierra pensar y elaborar propuestas formativas para los nuevos tiempos histórico-culturales, de modo igualitario y con aprendizajes cada vez más tecnológicos, a lo largo de toda la vida, en el vértigo de sus soportes y lenguajes que acelerada e incesantemente se renuevan.

Sin embargo, los contenidos, las formas de conocer como las tecnologías vigentes poseen fecha de expiración. El estado de precariedad aparece en la búsqueda constante en diversas facetas de la vida: esta realidad se halla atravesada no sólo por los flujos de información de Internet, sino también por la fabricación de productos, la movilidad de los viajes, el cuidado de la salud, la densidad demográfica en las urbes, el uso del ocio, la exploración mundana o seria con investigación y desarrollo de conocimientos científicos y tecnológicos, ya ubicados en un plano de una educación superior.

El aprendizaje se produce y renueva a lo largo de toda la vida, por lo cual todo conocimiento debería ser flexible, ya que es renovación y reconstrucción constantes. El mundo ha cambiado mucho y seguirá cambiando: la educación no consiste en aprobar asignaturas en las universidades, porque no ocurre solo dentro de los muros de una escuela. El conocimiento necesario para sobrevivir en el mundo actual del conocimiento es, tanto formalizado como tácito. Atraviesa la práctica cotidiana, se obtiene en interacción factual y virtual, se confronta en la experiencia compartida, - sin tener mayor conciencia de que se lo adquiere-, donde se lo mejora, recrea...

Este conocimiento vivencial debería combinarse con el teórico y abstracto para brindar herramientas a niños y jóvenes, adultos y adultas, para aumentar su capital cultural 
(Bourdieu, 1997) y enfrentar, con relativas garantías, la solución de problemas que la vida pone por delante.

La producción y la distribución del conocimiento tiene un costo cultural, social y cognitivo, además de económico, tanto para países y regiones, como para personas y grupos. Sin un compromiso en estas áreas, así como un sostenido apoyo financiero, ningún centro de enseñanza e investigación de un país podrá responder a los desafíos planteados por la aparición de la sociedad de la big data y economía del conocimiento.

\section{Algunas categorías para pensar la educación del futuro en una sociedad alternativa}

del conocimiento deberíanenfrentar muchos y enormes problemas globales que, lejos de resolverse, parecen agravarse. Entre otros, (Bunge, 1999) son:

1. El dominio económico progresivamente intenso y global de corporaciones transnacionales hegemónicas con el debilitamiento de las economías locales y el poder de la gente común.

2. La marginación política de las mayorías desilusionadas frente a los partidos políticos tradicionales, con el consiguiente debilitamiento de valores éticos e ideales democráticos y la aparición de totalitarismos (violentos) a escala planetaria.

3. El creciente deterioro del medio ambiente, debido a la ausencia de normativas nacionales e internacionales sobre temas centrales como la degradación de los ecosistemas, acelerado cambio climático, agotamiento de recursos naturales no renovables (como los energéticos), extinción de bosques, uso de pesticidas y fertilizantes, desertificación, pérdida de diversidad biológica y cultural, etc., sin toma de decisiones que reviertan las situaciones descritas.

4. El continuo aumento del armamentismo y guerras circunscritas en regiones; desocupación y aparición de enfermedades nuevas.

5. El disciplinamiento cultural establece modos de pensar, valores y aspiraciones de distribución uniforme a través de la publicidad y el "supermercadismo", lo que configura la cultura híbrida global. 
Si bien la idea y la práctica de la interacción telemática ha demostrado, por diferentes investigaciones empíricas, que coadyuva a logros muy interesantes, no pueden dejarse de lado diversos problemas serios que continúan: división mundial entre los “conectados y los desconectados", segregación entre varones y mujeres, zonas urbanas y rurales, entre otras diferenciaciones sociales, que globalizados, impide extender una "democracia cultural" , tanto de bienes materiales y simbólicos(auténticos como falsificados), en el acceso y consumo popular.

Incorporar las categorías de análisis de contradicción, co-determinación, reproducción crítica, cambio, trabajo y praxis aún no es materia frecuente en los análisis de los programas de educación virtuales (tampoco en los convencionales). Sin embargo, son centrales para pensar y anticipar diseños de una educación mediada por tecnologías en un futuro, que ya es presente.

Otras categorías fundamentales a la hora de dicha prospectiva en formato de síntesis creativa, podrían ser:

1) Formación para la sustentabilidad, idea que, si bien proviene del campo económico y ecológico, se instala definitivamente en el campo filosófico y sociológico de vinculación con la educación, pensando en "una educación sustentable para la sobrevivencia del planeta" y, por ende, convertir a los ciudadanos y ciudadanas en impulsores y sujetos activos de cambios en la historia, la cultura y la vida en sociedad, y otros.

2) Inter/trans-disciplinariedad para la consideración epistemológica en la construcción del saber, al incluir las categorías de trans-culturalidad, interculturalidad y trans-versalidad, complejidad y holismo.

3) Diálogo dentro de una praxis reflexiva, considerando las categorías de análisis (fenomenología hegeliana) de determinación, contradicción, necesidad y posibilidad.

4) Ciudadanía emergente en el contexto global, que implica abordar el diseño de un proyecto socio-político-educativo para la participación y la diferencia.

5) Planetarización, que implica que la educación es para el mundo o eco-pedagogía. Ellosignifica la superación de la defensa de los intereses y valores particulares a corto 
plazo y la comprensión de que la solidaridad y la protección global de la diversidad biológica y cultural, requisito imprescindible para y dada por una auténtica formación de personas y grupos.

6) Virtualidad, para una educación basada en software, inteligencia artificial y derivados, basados en la investigación científica y la tecnología digital de aplicación analítica, convincente, prudente,inquisitiva,y demás.

7) Globalización articulada con la cultura local, que modifica la política, la economía, la cultura, la historia y, por ende, la educación. Lo global y lo local se funden en una nueva realidad: lo glocal, donde el rol descentralizado de las entidades pequeñas, de los gobiernos municipales y del régimen de colaboración de las configuraciones en redes es central para una práctica formativa pertinente.

8) Inclusión en las propuestas formativas virtuales nuevas bases de conocimiento, acciones, disposiciones o actitudes que apuntan a un profesionalismo interactivo, autónomo y maduro, para la toma de decisiones dentro de una cultura de colaboración, de ayuda y de respaldo.

\section{3. ¿Cuál es la sociedad del conocimiento alternativa?}

Este interrogante surge frente al nuevo y ubicuo paradigma tecnológico de una sociedad de la información y conocimiento, donde la "capacidad de innovación", - léase con un desarrollo capital simbólico (Bourdieu, 1997), percibido como valor efectivo y pertinente, debería superar estadios no equitativos para muchas regiones y sectores del mundo respecto de lo ofrecido por las sociedades hegemónicas como "modelo a adoptar". 
La metáfora de pensamiento y acción para un paradigma socio-tecnológico educativo alternativo, para muchos es homologable a un rizoma ${ }^{6}$.

La "imaginería" del rizoma se muestra donde se dan conexiones entre cadenas semióticas y/o redes tecnológicas, como organizaciones de poder según las circunstancias relativas a las artes, las ciencias, la tecnología y los contextos sociales.

Una cadena semiótica es como un tubérculo que va acumulando actos muy diversos, no solo lingüístico-comunicacionales, sino también perceptivos, miméticos, sociales y cognitivos. No existe el lenguaje de por sí, ni tampoco universales lingüísticos, sino un conjunto particular de dialectos, argots, jergas y lenguajes especializados "como una toma de poder por parte de un idioma predominante dentro de una multiplicidad sociopolítica” (Deleuze, 2002). ${ }^{7}$

El tránsito a un paradigma social, tecnológico y educativo alternativo se basa en una concepción rizomática de desarrollo sostenible, que a pesar de su impredictibilidad. combinaría nuevas fuentes de energía, mayor efectividad en la selección y el uso de los recursos, la producción y el consumo sustentable, dentro de una dimensión ambiental y ética de la vida, opuesta a la tendencia "global-fundamentalistas-mercantiles-neoliberales" que se arrastran desde mediados del siglo XX, como buscadores de ganancias

Para concretar el aprendizaje a lo largo de la vida, con y para la formación plena de la ciudadanía emergente en la sociedad red de los flujos de información, de la cultura digital del conocimiento, la pregunta es cuál es, qué clase de sociedad del conocimiento se está construyendo, se está transitando o a cuál se está arribando, interrogante necesario para precisar varios puntos: qué clase de conocimiento hubo antes, existe ahora y cuál es el deseado/necesario para configurar la sociedad que los tiempos en cuestión requieren.

\footnotetext{
6“"El rizoma como tallo subterráneo es totalmente diferente de las raíces y radículas. Los bulbos y los tubérculos son rizomas [...] El rizoma asume formas muy dispares, en formaciones superficiales ramificadas y relaciones discontinuas, fracturadas, no lineales [...] Todo punto de un rizoma puede conectarse a cualquier otro y $[\ldots]$ en esto se diferencia mucho del árbol o de la raíz, que señalan un punto, establecen un orden.”

${ }^{7}$ Op. cit

Rev. educ. super. sur glob-RESUR $N^{\circ} 4$ jul. -dic. 2017 e009 ISSN 2393-6789
} 
Referirse a una sociedad alternativa de conocimiento, entonces, significa considerar diferentes variables en interdependencia para su configuración. Se deberían tomar decisiones sinceras y realistas que aseguren, voluntad sociopolítica consensuada y planeamientos estratégicos mediante, proyecciones futuras autosostenibles y autosustentables, sobre en las instituciones de nivel superior (antes invertir en educación, infraestructura tecnológica y de telecomunicaciones), en ciencia y tecnología, investigación y desarrollo, por nombrar las áreas más salientes.

La educación con TIC y formatos asociados en línea podría convertirse en una propuesta de elección. Implica una propuesta que conjuga una inter-disciplina para el estudio-trabajo de su campo. Al mismo tiempo, una concertación fortalecida de políticas sectoriales comprometidas (con la menor cantidad posible de dobles mensajes, ambivalencias y contradicciones.

La construcción de una sociedad(alternativa) de conocimiento en la cultura digital alternativa demandaría así, una perspectiva crítica y éticade lo ciber-sociocultural,

para un diálogo transversal, con preguntas e interrogantes inéditos, hacia una reflexión, análisis y reelaboración de propuestas, o sea a explorar y probar lo no conocido.

Dentro de una visión macro, se insiste (Carr, 1993) en que estas búsquedas se constituyan en actividades éticas que lleven a la transformación social. Por ende, se trata del campo de la investigación-acción socio-tecnológica, que debe preguntarse sobre lo social, y así lo formativo.

Con esa responsabilidad, se tiende hacia la reorientación de la actual investigación científico-tecnológica como elemento central constructivo y como estrategia que responda de modo significativo a una nueva o alternativa sociedad de la información y del conocimiento.

La sociedad alternativa del conocimiento es la sociedad de la ética de la equidad en la creación, la distribución y el uso de los recursos dentro de un equilibrio sustentable intrageneracional e inter-generacional. Es la sociedad como los tiempos reclaman, estimuladora de la expresión y el fortalecimiento de la identidad, que no debería estar separada de una cultura crítica, de info-inclusión y expresión de todas las prácticas sociales existentes más allá de quienes las hayan producido. Es decir, de una racionalidad comunicativa (Habermas, 1989), corporizada en el/los software (¿se podrá?)

Además de la pregunta anterior acerca de qué tipo de sociedad del conocimiento, aparece otro interrogante: ¿la sociedad del conocimiento es una herramienta político-económica, un constructo o simplemente un concepto vacío? 
Se trata de grandes retos trans disciplinarios para pensadores sociales, sociólogos, politólogos, filósofos, antropólogos, educadores/as, analistas de sistemas, economistas, etcétera, que deben estudiar, profundizar, conjugar y reinterpretar la comprensión de los contenidos históricos, filosófico-epistemológicos, que impactan en la educación virtual.

Esta propuesta crítica superaría las "historias oficiales y ocultas" dentro de una nueva híper-sociología que estudia y revisa "expectativas colectivas", socialmente constituidas (Bourdieu, 1991), por corporización informacional, que penetran cada vez más por una ciber-infraestructura de lo software en la totalidad de las actividades humanas. Donde se resemantizarían las creencias y conceptos, valores y actitudes arrastrados históricamente, y demás.

Si la sociedad del conocimiento se caracteriza por la centralidad de los escenarios de lo intangible, de las tecnologías invisibles (o estrategias de pensamiento en nuestra mente o mindware, sin las cuales cualquier hardware y software de Internet y las TIC no podrían operar), se impone configurar alternativas de índole significativa e igualitaria para desarrollar en personas, grupos y organizaciones una mayor productividad y reflexividad (Giddens, 1997)de perfil cosmopolita (pero no conquistador-hegemónico) y con una lógica incluyente que supere lo sectario y excluyente manifestado por el mercado global.

\section{¿En qué radica lo alternativo?}

La ciencia y la tecnología con sus protagonistas deben articular puentes entre el conocimiento científico-tecnológico y la vida cotidiana, para integrar saberes y construir posibilidades de desarrollo sociocultural hacia un desarrollo integral de las personas y, de modo especial, conducir a la comprensión de la relación compleja del mundo de los grandes flujos informacionales globales y la vida cotidiana.

Mientras la sociedad de la información acentúa lo tecnológico del software, lo específico de un modelo alternativo de desarrollo de "una" sociedad de conocimiento (no sólo habría varias, sino diferentes o alternativas) es hoy, valerse de la cultura digital y las humanidades digitales para la acción del conocimiento en el propio conocimiento, o de 
profundización del conocimiento al interior del saber, como principal motor de productividad y creatividad, impulsado hacia un desarrollo sostenido y autosustentable dado por la creatividad que el siglo XXI necesita.

Dentro de este contexto se piensa que una sociedad alternativa de conocimiento respondería a los cambios irreversibles en todas las áreas del saber dentro de un marco de una "nueva ecología de aprendizajes y de una cartografía sociocultural diferente.

Significa superar el proyecto hegemónico de las TIC, en forma, contenido y misión, para dar paso a diferentes proyectos de formatos diversos de interacción virtual, donde se recrean espacios, mundos, contextos múltiples, etc. con diseños particulares y generación de posibilidades de interacción equitativas y pertinentes.

Otorgar otro sentido a la producción, la distribución y el uso social de la información en una sociedad alternativa del conocimiento constituye un tema controvertido debido a la resemantización de la tecnología y las TIC. Es decir, significa reconocer que encierran diversos capitales: económico (son bienes), social (implican redes de relaciones socioelectrónicas) y cultural (con conocimientos generales y especializados), que es lo que establece una real diferencia en términos de producir un cambio sociocultural ${ }^{8}$.

Parecería que el desafío es “completar la revolución incompleta”(Dertouzos, 2003) ${ }^{9}$.Si el software es ubicuo y atraviesa la vida sin notarse, la pregunta es: ¿se estará mejor? ¿O sólo existirá aumento de la eficiencia y la productividad? Si bien se ahorrará tiempo, ¿qué se hará con todo el tiempo que se ahorra? ¿Trabajar más y de un modo uniforme? ¿Las computadoras nos ayudarán a ser más humanos? ¿O la humanidad se ahogará en mayores y veloces cantidades de big data? ¿Cuáles son los beneficios? ¿Habrá un cambio social cualitativamente nuevo, un nuevo orden social? una reformulación (¿evolutiva?, ¿revolucionaria?), una creación o recreación histórico-sociocultural?¿del conocimiento, de la vida?

\footnotetext{
${ }^{8}$ El cambio socio-cultural, tecnológico y educativo es una consecuencia del contexto histórico del siglo XXI, en un tránsito a la 4ta revolución industrial de la Big data, y los nuevos media sostenidos por el software y algoritmos en continua transformación, y desconocimiento de sus proyecciones futuras.

${ }^{9}$ Op cit. 
Como no tenemos, aun reales categorías nuevas para responder, es que tal vez, se estimule un repaso de los modos de conocimiento, para explorarlos a la luz del encuadre referido.

\section{Modos de conocimiento}

La sociedad del conocimiento que se propone como opción alternativa pasa por reconocer infinitas incógnitas y estar abiertos para legitimar otros modos de conocer o producir saber. Entre ellos:

1. La superación de la concepción de la ciencia de base matemática por una visión transdisciplinaria holista e integral donde el método hermenéutico inscripto en las humanidades digitales, sea la guía para la investigación cuanti y cualitativa del saber. El saber sería como estar en posesión de la verdad y la verdad es un proceso con acciones por desocultar. La ciencia alternativa descansaría en una ontología sistémica donde el centro del saber se halla en la interrelación de los fenómenos que explica. Se provoca el entendimiento dialéctico del objeto y el sujeto en el contexto socio-histórico para arribar a interpretaciones teórico prácticas provisorias mientras investiga.

2. El continuo devenir recursivo mantiene la relación de lo que se produce, dónde se produce (en espacio físico o virtual) y quién lo produce, sin buscar en la realidad una explicación absoluta ni final de lo producido. Los postmodernistas critican el paradigma modernista anterior y rechazan todo control objetivo y absoluto de la ciencia en la producción del conocimiento, al tiempo que dejan abierto el camino interdisciplinario ${ }^{10}$ como mecanismo alternativo de investigación socio-histórica-constructivista no solo para el desarrollo científico-tecnológico, sino para la comprensión de los fenómenos, los avances del entendimiento humano y el desarrollo autosustentable al interior de las estructuras sociales.

3. El reconocimiento de la influencia del saber cotidiano en las interpretaciones y acciones de personas legas o expertas. Se trata del conocimiento que se adquiere en la

\footnotetext{
${ }^{10}$ Las razones de la interdisciplinariedad se apoyan en tres razones fundamentales: la búsqueda de la coherencia del conocimiento en un todo unificado; la propia evolución acumulativa del conocimiento como fusión de perspectivas separadas; y la visión pragmática para la solución de los problemas básicos del hombre
} y la sociedad.

Rev. educ. super. sur glob-RESUR N4 jul.-dic. 2017 e009 ISSN 2393-6789 
experiencia diaria, compuesta de concepciones débiles o erróneas, conocimientos inconexos, superficiales, no sistemáticos y acríticos. Considerar el saber tecnológico con existencia propia y en buena medida, su carácter tácito ${ }^{11}$,supera la conceptualización cientificista por largo tiempo aceptada de la posición de "tecnología = ciencia aplicada" - aún en debate- para reconocer los componentes no científicos ${ }^{12} \mathrm{del}$ conocimiento tecnológico como sistema de pensamiento y actuación particular e independiente de la ciencia. También existen diferencias con el saber técnico, que es aleatorio, rectificado y procedimental, mientras que el saber científico es formal y universal.

El pensamiento tecnológico se diferencia entonces del científico básicamente por las ideas tecnológicas que se plasman en el "diseño" -implementado luego por técnicas- para producir artefactos duros (maquinarias y equipos) y sistemas procesuales blandos (sistemas instruccionales apoyados en software y plataformas). El conocimiento tecnológico incorpora las dimensiones de la observación directa y la experiencia sistemática de trabajo bajo condiciones variadas y/o circunstancias de primera mano. También, las actividades sistemáticas cuidadosamente diseñadas (aunque no científicas) y el uso de métodos experienciales. Asimismo, realza la comprensión de buena fe por contrastación empírica de procedimientos ${ }^{13} \mathrm{y}$, sobre todo, la intuición y la imaginación (modos implícitos de una persona no derivables de una comprensión científica), acerca de cuál podría ser el diseño, el procedimiento o la aplicación más apropiados para realizar o satisfacer una tarea tecnológica.

4. La metodología fenomenológica (o "etno-metodológica") aborda y hace explícita la verdad de la experiencia primaria del mundo social. La aprehensión del mundo social como mundo natural a través de la hermenéutica construye relaciones que estructuran prácticas objetivas y representaciones de las mismas. En particular, el conocimiento primario práctico del mundo familiar y los presupuestos tácitamente asumidos

\footnotetext{
${ }^{11}$ Se apunta al pensamiento no verbal como "el ojo de la mente", donde lo visionario, imaginario y creativo aparece como lo crucial de la facultad humana productora de tecnología.

${ }^{12}$ Se refiere a la intuición, a la creatividad, a la inclusión de técnicas artesanales ancestrales, etcétera

${ }^{13}$ Alerta a las fallas tecnológicas porque resultan más por juicios erróneos de las personas que por cálculos erróneos.
}

Rev. educ. super. sur glob-RESUR No4 jul.-dic. 2017 e009 ISSN 2393-6789 
configuran el mundo social en su carácter evidente (Bourdieu, 1972). La práctica social es concebida como pura creatividad a partir de la relación dialéctica y de síntesis entre el sujeto y el objeto donde no hay ruptura entre conocimiento "práctico" y conocimiento "científico" de los fenómenos sociales.

5. La centralidad de las redes de conocimiento, -factuales y virtuales-, dentro de las características complejas y contradictorias de los sistemas de producción de saber en general y, en particular, de ciencia y tecnología, vinculados al entorno social, exigen diseños organizacionales y de programas de investigación flexibles y adaptables a los cambios imprevisibles.

Sin embargo, también se insiste en la necesidad de una ruptura con las representaciones inmediatas y "familiares" de la vida social como condición para una auténtica ciencia social, para que se puedan revisitar paradigmas mentales existentes personal y colectivamente.

De este modo, la atención en favor de una ruptura epistemológica de las representaciones del sentido común no implica llevar la explicación epistemológica y sociológica hacia una "neutralidad ética". De este modo,a ruptura representada por dicho análisis se dirige hacia una propuesta de sociedad en revisión permanente de sus partes y su dinámica, lo que significa realizar un análisis evaluativo y crítico de lo informacional.

Consecuentemente, los hechos sociales y educativos que se presentan en la interacción convergente de saberes mediados por tecnología electrónica ubicua necesitan ser "vigilados epistemológicamente" (Bachelard, 1979), en todos los fenómenos de la vida cotidiana.

Es necesario aquí apelar a las ciencias simbólicas, -al sostener que la vida social crea normas y representaciones, procesos y productos simbólicos de interacción situada, compartida y distribuida-, y las ciencias críticas-que requieren del contraste, la desmistificación y la deconstrucción de los hechos sociales, entre ellos, los flujos de información. 
La ruptura con las representaciones espontáneas que propondría la explicación del hecho educativo mediado por los nuevos medios, supone un punto de partida socio-históricoepistemológico adecuado para discutir el discurso un contexto de reflexión de los entornos digitales, es decir, no debería estar sujeto a ideas de un orden establecido.

Dicho de otro modo, para que la dominación no legitime lo indiscutible de las ideas expuestas, es necesario legitimar el conflicto como oportunidad y "líneas de fuga" (Guattari, 2013) como espacio de confrontación madura entre diversas posiciones a modo de creación y desplegar reflexividad.

Creemos en un posible y real aprovechamiento y uso inteligente (Fainholc, 2004)de las nuevas tecnologías para generar ambientes socioculturales alternativos $\mathrm{y}$, por ende, aprendizajes digitales poseedores de un nuevo sentido para personas y grupos, autoreguladores del proceso formativo - por un trabajo discursivo pedagógico ${ }^{14}$ mediado-, acorde con las necesidades y la dinámica de la contemporaneidad, que reclama más inteligencia, lucidez y sensibilidad.

\section{Diseñar un futuro}

Significa hoy crear y anticipar un abanico de futuros como contextos o entornos factuales y electrónicos de modo estratégico para la toma de decisiones y estar preparados para enfrentar posibles contingencias. Al planificar escenarios, -método alternativo para comprender mejor el futuro y, en consecuencia, adaptarse más efectivamente a los cambios-, se obtiene una serie de proyecciones efectivas para dominar y revisar situaciones críticas entrecruzadas por lógicas diferentes.

Para América latina, (Fainholc, 2016) los entornos culturales aparecen en un mix de hibridaciones diversas representadas por la oralidad de la cultura popular (la música, los cuentos, chismes y chistes, entre otros); la cultura letrada que aún es la más valorada, aunque presenta reduccionismos varios (Fainholc, 2015) hoy subsumidos a todos estos formatos de Internet.

\footnotetext{
${ }^{14}$ El trabajo discursivo: es la expresión a través de palabras, imágenes, espacios y objetos virtuales para comunicar y comunicarse al interior de las relaciones sociales. El discurso pedagógico: son las propuestas teóricas, metodológicas y prácticas destinadas a promover un aprendizaje que implica al máximo las capacidades de quien aprende. La mediación pedagógica: representa la promoción de una educación concebida como participación creativa (que supera la pasividad) y expresiva (o con capacidad de comunicarse en distintos registros), dentro de un contexto de interaprendizaje.

Rev. educ. super. sur glob-RESUR No4 jul.-dic. 2017 e009 ISSN 2393-6789
} 
$\mathrm{Si}$ se trata de configurar una sociedad alternativa del conocimiento para los países emergentes y complementar, completar y contrarrestar la sociedad "oficial" del conocimiento, producida y generalizada por los países centrales, la educación virtual coadyuva a un escenario de futuro ya no tan lejano, que podría: 1) intentar superar la exclusión y/o completar la oferta de los sistemas educativos convencionales, ya anacrónicos con relación a las mutaciones culturales que presentan las sociedades; y 2) profundizar la democratización respecto de las mayorías, observando las subculturas cotidianas, al otorgar posibilidades para apropiarse de saberes a través de nuevas mediaciones en cuanto soportes, lenguajes y narrativas.

Se contribuye así a no ignorar que, en ciertas condiciones socioculturales, la posesión de un saber, un descubrimiento científico, la utilización de una información, la invención de una idea, pueden convertirse en actos decisivos, como innovadores o transformadores de la praxis socio-histórica. Representaría reconocer que el conocimiento permite acceder y otorga poder (Foucault, 1995).

El conocimiento se vincula y es condicionado, determinado y producido por todas las partes que estructuran la cultura, la organización social, la praxis histórica, como también es condicionante, determinante y productor de las mismas, lo que demuestra, de modo fascinante, la aventura del conocimiento científico-tecnológico actual.

No obstante, continúan las preguntas acerca de qué diferentes maneras de construir saber provocan las mediaciones tecnológicas, para no caer en simplificaciones al contraponer -al estilo de "apocalípticos e integrados" de Eco- lo nefasto de la saturación de superficialidad de la imagen alienante de las TIC e Internet, al reconocer que establecen nuevos modos de conocer a través de la tecnología y las TIC.

Los centros de enseñanza superior desempeñan un papel central en las sociedades del conocimiento, en sus funciones de producción, difusión, investigación y transferencia del saber. Las universidades ya no responden a modelos únicos y su oferta educativa se ha diversificado en la medida en la que los conocimientos se especializaron y profundizaron 
(en institutos politécnicos, escuelas especializadas de ingenieros, escuelas de ciencias empresariales y management, laboratorios de investigación, entre otros).

\section{¿Para qué se educa?}

Los problemas que plantea y que se le plantean a la educación son analizados y debatidos por todas las sociedades actuales.

¿Para qué educar? Apertura y acceso a la información seguida de uso inteligente y reflexivo de las TIC deberían servir para erradicar ignorancia, marginaciones y exclusiones.

Ignorancia y libertad son conceptos mutuamente excluyentes, pues quien ignora cuáles son sus opciones está imposibilitado para elegir entre ellas.

La participación democrática se da y es puerta del saber cuándo el conocimiento es asequible y democrático.

Sin embargo, no siempre se formula el interrogante que está en la base y en la esencia de lo enunciado y que subyace al fenómeno educativo: ¿cuál es el objetivo fundamental que debe cumplir la formación de personas y grupos en programas educativos electrónicos?

Entonces, ¿para qué se educa? Para que cada hombre y cada mujer sea más persona (Burbules, 2001).

Se trata de potenciar la posibilidad de transmitir y recrear a las nuevas generaciones respecto de lo específico de la experiencia humana, extrayendo de cada ser humano lo mejor o más valioso que lo caracteriza como persona, o sea, se rescata al sujeto moral y cultural.

Se educa para que en las diversas propuestas educativas electrónicas se amplifique el destino del ser humano, al fortalecer elpensamiento crítico $^{15}$ y para decidir qué aceptar y creer, porque se evalúan de modo autorregulado las ideas. Se llega, así, a una interpretación, análisis, inferencia y explicación de las evidencias, en sus conceptos,

\footnotetext{
${ }^{15}$ El pensador crítico es el inquisitivo, de raciocinio confiable, de mente abierta, flexible, evalúa con justicia, honesto en reconocer sus prejuicios, prudente para emitir juicios, dispuesto a reconsiderar los problemas, diligente en la búsqueda de información relevante, razonable en la selección de criterios, enfocado a investigar y persistente en la búsqueda de resultados precisos respecto del tema/materia. Ver:
} www.eduteka.org

Rev. educ. super. sur glob-RESUR N 4 jul. - dic. 2017 e009 ISSN 2393-6789 
metodologías y contextos sobre los que se basan los juicios. Es decir, ello implica reflexionar sobre la validez de la comprensión que se posee y se replantea acerca del mundo.

Ser humano implica la práctica crítico-reflexiva y metodológica del pensamiento: hoy la tecnología ayuda a potenciar estas actividades si se posee conciencia de ello, además de acceso a la conectividad y de una guía orientativa en la cultura digital.

La cuestión es analizar si tales tecnologías pueden "hacer más" por mejorar a la humanidad y coadyuvar, entre otros factores, a configurar a través de su interacción "mejores" personas.

Existen varias dimensiones históricamente consideradas que significan "ser humano" (Dertouzos, 2003) ${ }^{16}$ : la "razón" o el pensamiento racional, que se halla por detrás de la ciencia y la tecnología; el "sentimiento", que impulsa las artes y las humanidades; la "fe" que ayuda a explicar lo inexplicable; y la "acción” física o los actos que se realizan.

Creemos que estamos frente a una revolución cognitivo-sociocultural y moral que replantea no sólo las dimensiones de la vida sociopolítica sino la configuración de nuevas subjetividades al interior de una vida de bordes fractales y rizomáticos, de implicaciones epistemológicas, éticas y culturales no del todo identificadas y estudiadas.

Un nuevo paradigma educativo para una sociedad alternativa del conocimiento debería contener, entre otros, los siguientes puntos:

1. la creación y la reformulación de imágenes del mundo que reconozcan y defiendan la educación como derecho social privilegiado para alcanzar igualdad social y política con equidad y dentro de una multi/ interculturalidad planetaria, que enfatice el respeto a los derechos individuales y colectivos, políticos, económicos, educativo-culturales y ecológicos, en dignidad para todos los seres humanos;

2. la formación de cuadros dirigentes acordes con la complejidad de la estructura de la vida actual, especialistas en muy diversas y variadas profesiones dentro de marcos democráticos como un medio para organizar las sociedades de manera justa, ética y digna;

${ }^{16}$ Op. cit.

Rev. educ. super. sur glob-RESUR N 4 jul. -dic. 2017 e009 ISSN 2393-6789 
3. entender que la ciencia y la tecnología no son más que procesos y productos sociales que permiten aprehender la realidad a través de la actividad humana no neutral, con lo cual se debería tomar conciencia de las consecuencias, buscadas o no, que su desarrollo genera. La actividad científico-tecnológica éticamente comprometida con la vida transformaría la lógica del cambio socio-tecnológico capitalista-supeditado al principio de una mayor acumulación y concentración de capital- hacia un nuevo principio de satisfacción de necesidades humanas con vocación humanista.

\section{Para finalizar.}

El cuadro principista enunciado ha intentado configurar una propuesta de un paradigma educativo para una sociedad alternativa del conocimiento, dentro de algunos parámetros provisorios.

La misión apuntaría a encontrar algún rumbo para ello: anticiparlo y dibujarlo, prestando atención a las decisiones a evaluarse y tomarse y las acciones humanas a ejecutarse.

Lo que se configura y visualiza a partir de los actos políticos, formativos y éticos, que enfatizan tanto rasgos como propiedades (que como constructos que son, también oscurecen otros tantos), contingencias y otros, es analizar y experimentar, hoy en la cultura digital del software, su valor.

De modo sencillo: se necesita mucha educación para poder lidiar con tantos interrogantes inéditos e intentar la creación de síntesis creativas.

Se trata, finalmente, de desafíos socio-formativos de mucho compromiso: perseverar, invertir e inscribir los esfuerzos educativos en general y en línea en particular en la esfera sociopolítica de enseñar y aprender a formular preguntas.

La pregunta, único resorte de búsqueda, caracteriza a la especie humana, a diferencia de las respuestas que, si bien conforman perfiles de personas y objetos a largo o corto tiempo, son frágiles y temporarias. 
Re - construir una alternativa sociedad de conocimiento, es central para los tiempos digitales que se viven, a fin de entender y darles algún lugar propio alas tecnologías de modo apropiado, sinérgico, abierto y utópico, según escenarios y actores específicos.

\section{Referencias}

Arnowitz, S. (comp.) (1998). Tecnociencia y cibercultura. La interrogación entre cultura, tecnología y ciencia. Barcelona: Paidós.

Bachelard, G. (1979). La formación del espíritu científico. México: Siglo XXI.

Bourdieu, P. (1997). Capital Cultural, Escuela y Espacio Social. México: Siglo XXI.

Bourdieu, P. (1991). El sentido de la práctica. Madrid : Taurus.

Bourdieu, P. (1972). Esquisse d’une théorie de la pratique. Ginebra: Droz.

Bunge, M. (1999). Las Ciencias Sociales en discusión, una perspectiva filosófica. Buenos Aires: Sudamericana.

Bunge, M. (1997). Ciencia, Técnica y Desarrollo. Buenos Aires: Sudamericana.

Bunge, M. (1996). Sociología de la ciencia. Buenos Aires: Siglo Veinte.

Bunge, M. (1999). Las Ciencias Sociales en Discusión: una perspectiva filosófica. Buenos Aires: Sudamericana.

Burbules, N. (2001). Non-ideal theory and the philosophy of education. Urbana-

Champaign., USA: University of Illinois. Recuperado de :

http://ovpes.org/wp-content/uploads/2015/06/Burbules_2015.pdf

Carr, W. (1993). Calidad de la enseñanza e investigación-acción. Sevilla: Díada.

Ciaspucio, H. (1996). El conocimiento tecnológico. Revista Redes, 3(6), 177-194

Deleuze, G. y Guattari, F. (1977). Rizoma. Valencia, Minuit.

Deleuze, G y Guattari, F. (2002). Mil mesetas, capitalismo y esquizofrenia. Valencia: Pretextos.

Dertouzos, M (2003). La revolución incompleta. Madrid, España: Fondo de Cultura Económica de España.

Fainholc, B (2016). Big data. Recuperado de:

http://webquestorgar.blogspot.com.ar/2016/04/big-data.html

Fainholc, B (2016). Presente y futuro latinoamericano de la enseñanza y el aprendizaje en entornos virtuales referidos a educación universitaria. 
Revista de Educación a Distancia, (48). Recuperado de http://www.um.es/ead/red/48/fainholc.pdf

Fainholc, B. (2015). Los reduccionismos epistemológicos de la educación a distancia virtual. Recuperado de http://webquestorgar.blogspot.com.ar/2015/08/losreduccionismos-epistemologicos-de.html

Fainholc, B. (2007). Aprendizaje electrónico mixto: una propuesta educativa de síntesis creativa. Buenos Aires: CEDIPROE.

Fainholc, B. (2004). De cómo nos imaginamos las condiciones necesarias para un tránsito a la práctica educativa cotidiana de calidad desde la excepción de las TIC hacia su invisibilidad en el 2025. EDUCTEC 2004. Educar con tecnologías, de lo excepcional a lo cotidiano. Barcelona: Universidad de Barcelona.

Felix, G. (2013). Líneas de fuga. Por otro mundo de posibles. Bs As.: Cactus.

Foucault, M. (1995). Un diálogo sobre el poder. Madrid: Alianza.

Giddens, A. (1997). Vivir en una sociedad post-tradicional. En U. Beck, A. Giddens y S. Lash (eds.), Modernización reflexiva. Madrid: Alianza.

Habermas , J. (1989). Teoria comunicativa. Madrid: Taurus. 2 tomos

Habermas, J. (1990). The Philosophical Discourse of Modernity. Cambridge: USA.MIT Press

Habermas, J. (1988). Conocimiento e interés. Buenos Aires: Taurus.

Habermas, J. (1986). Ciencia y tecnología como Ideología. Madrid: Tecno.

Manovich, L (2013). El software es el mensaje. Software takes command. New York:

Bloomsbury Academic

Manovich , L. (2001). The language of new media, USA: MIT. Trad. al español: El lenguaje de los nuevos medios de comunicación, 2007. Bs As: Paidós.

Polanyi, M. (1975). The mind's eye: non-verbal thought in technology. En The origins of knowledge and imagination. Chicago: University of Chicago. 